\title{
Rare gene variants in a patient with azathioprine-induced lethal myelosuppression
}

\author{
Xiaoxue Yang ${ }^{1} \cdot$ Heng $\mathrm{Xu}^{2} \cdot$ Jun Yang $^{3} \cdot \mathrm{Li}$ Yang $^{1}$ (D
}

Received: 29 July 2017 / Accepted: 16 August 2017 /Published online: 22 August 2017

(C) The Author(s) 2017. This article is an open access publication

\section{Dear Editor,}

A 46-year-old Chinese male patient was diagnosed with autoimmune hepatitis - primary biliary cholangitis overlap syndrome at the first admission on Apr 22nd 2016. He was treated with ursodeoxycholic acid, followed by prednisolone and azathioprine (Fig. 1a). He was admitted again with fever and sore throat on Sept 15th, showing visible throat swelling. Notably, a sharp drop of blood cells was observed, reaching the diagnostic criteria of grade 4 myelosuppression (Fig. 1a), with $0.18 \times 10^{9} / \mathrm{L}$ for neutrophilic granulocytes. Azathioprine and prednisolone were stopped immediately, while human granulocyte colony-stimulating factor and recombinant human thrombopoietin were prescribed to increase blood cells. However, the patient still suffered a life-threatening progressive decrease of blood cells. The lowest level of neutrophilic granulocytes, reticulocytes, and white blood cells reached $0.01 \times 10^{9} / \mathrm{L}, 0.0040 \times 10^{12} / \mathrm{L}, 0.25 \times 10^{9} / \mathrm{L}$, respectively, on Sept 23rd, while the hemoglobin, platelets, and red blood cells dropped to the lowest level at $54 \mathrm{~g} / \mathrm{L}, 22 * 10^{\wedge 9} / \mathrm{L}$, and $1.66 * 10^{\wedge 12} / \mathrm{L}$, respectively, on Oct 1 st (Fig. 1a). Moreover,

Li Yang

yangli_hx@scu.edu.cn

1 Department of Gastroenterology and Hepatology, West China Hospital, Sichuan University, Chengdu, Sichuan, People's Republic of China

2 Department of Laboratory Medicine, Precision Medicine Center, State Key Laboratory of Biotherapy and Precision Medicine Key Laboratory of Sichuan Province, West China Hospital, Sichuan University and Collaborative Innovation Center, Chengdu, Sichuan, China

3 Department of Pharmaceutical Sciences, St. Jude Children's Research Hospital, Memphis, TN, USA diffuse rash and severe alopecia were observed. Serious infections (Pseudomonas aeruginosa infection) also occurred during hospitalization. The blood counts recovered far more slowly than expected and it returned to normal until 25 days (Oct 10th) after therapy (Fig. 1a). We attempted to genotype the SNPs of NUDT15 (rs116855232) and TPMT (rs1142345) of this patient and found that this patient has NUDT1 $5^{\text {risk/risk }}$ $T P M T^{\text {wt } / \text { risk }}$ genotype (Fig. 1b).

The frequency of rs1142345 and rs116855232 exhibits largely ethnic differences. According to the large genetic variant screening in diverse ethnicities, the risk allele frequency of rs1142345 is high in Caucasians (4\%), Hispanics (4.8\%), and Africans (5.4\%) but low in East Asians (1.3\%), while that of rs116855232 is high in East Asians (10.4\%) and Hispanics $(7.1 \%)$ but rare in Caucasians $(0.46 \%)$ and Africans $(0.07 \%)$ (http://exac.broadinstitute.org/). Therefore, concurrence of rs1142345 and rs116855232 risk allele (at least homozygous for one SNP) is pretty rare (Fig. 1c), which have never been reported in thiopurine treatment before. Indeed, the frequency of the genotype we reported is $\sim 140.6$ per million in East Asians. The variant can induce activity deficiency of both TPMT and NUDT15 enzymes, thus reducing the degradation of 6-thioguanine nucleotides through different mechanisms [1]. Not surprisingly, the patient suffered severe lifethreatening myelosuppression with very early occurrence and long duration after azathioprine treatment. Therefore, lower thiopurine dosage should be used in patients with such genotype than those with $N U D T 15^{\text {risk/risk }}$ or TPMT $T^{\text {risk /risk }}$ alone [2]. However, guidelines for autoimmune liver diseases have not referred to NUDT15 genetic examinations before azathioprine treatment. Given that NUDT15 and TPMT are commercially available to be checked, more clinicians should be aware that it is important to detect both TPMT and NUDT15 SNPs before thiopurine treatment in autoimmune liver diseases, especially in East Asians and Hispanics. 
a Reticulocyte and red blood cells counts, hemoglobin concentration
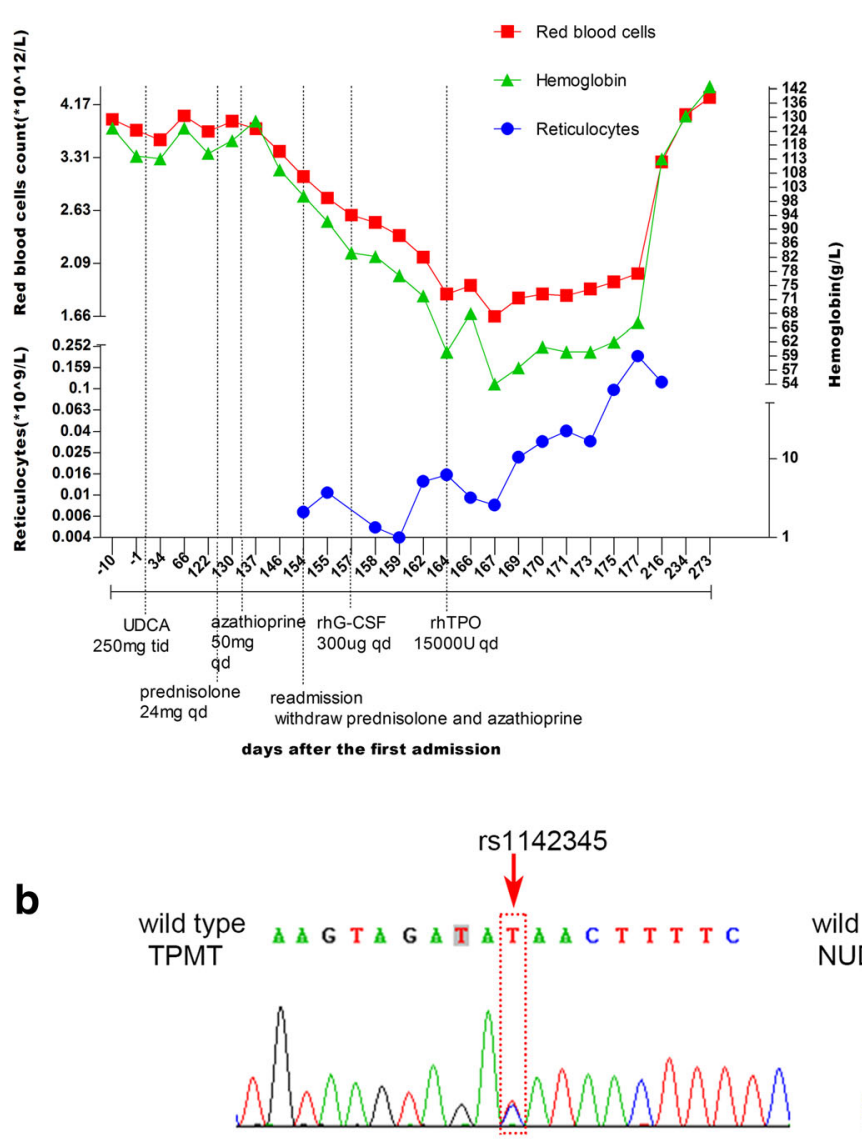

White blood cells, segmental neutrophils and platelets counts
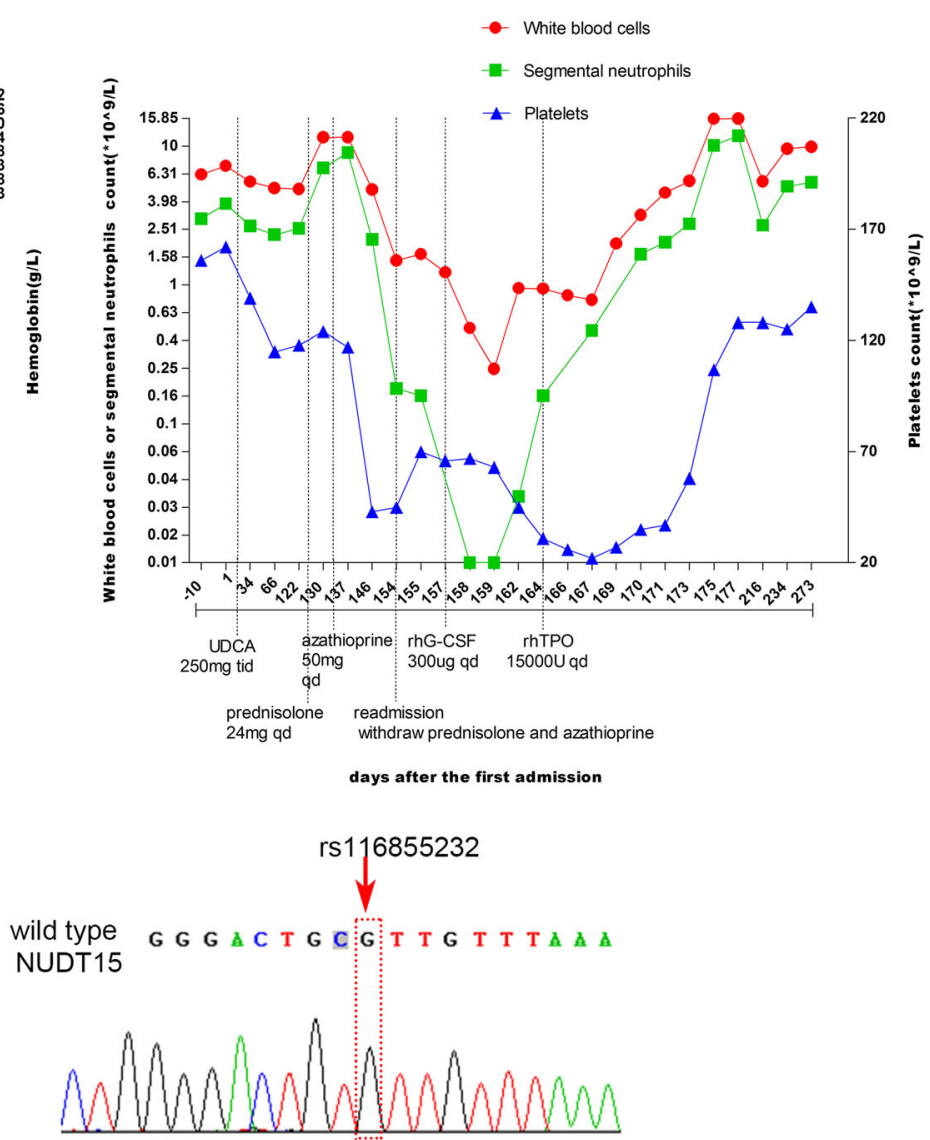

C

\begin{tabular}{|c|c|c|c|c|}
\hline No./million & Caucasians & Africans & East Asians & Hispanics \\
\hline TPMT $T^{\text {wt/risk }} N U D T 15^{\text {risk/risk }}$ & 0.85 & 0.03 & 140.6 & 242 \\
\hline TPMT $T^{\text {risk/risk }}$ NUDT15 $5^{\text {wt/risk }}$ & 7.36 & 2.04 & 17.6 & 163.6 \\
\hline TPMT $T^{\text {isk/risk }} N U D T 15^{\text {risk/risk }}$ & 0.034 & 0.0014 & 1.8 & 11.6 \\
\hline
\end{tabular}

Fig. 1 The changes of blood cells and gene testing of the patient. a The changes of white blood cells, neutrophilic granulocytes, red blood cells, reticulocytes, hemoglobin, and platelet in the clinical course. b The frequency of concurrence of rs1142345 and rs116855232 risk allele (at least homozygous for one SNP) in diverse ethnicities. c The NUDT15 and TPMT gene variants of the patient. The GenBank accession number of the TPMT and NUDT15 DNA are NG_012137.2 and NG_047021.1. Abbreviations: TPMT $=$ thiopurine S-methyltransferase; NUDT15 = nudix hydrolase 15; UDCA = ursodeoxycholic acid; rhG-CSF = Human Granulocyte Colony Stimulating Factor; rhTPO = Recombinant human thrombopoietin
Additionally, other less common SNPs in these two genes should be also considered, such as rs147390019 with an allele frequency of $1.7 \%$ in Hispanics [3].

Acknowledgements Thanks to our colleagues for their efforts and also acknowledge the cooperation from the patient.

\section{Compliance with ethical standards}

Conflict of interest The authors declare that they have no conflict of interest.
Grant support This study was supported by grants from National Natural Science Foundation of China (Grant No. 81570554 and 81522028).

Informed consent The patient gave informed consent for part of her medical history to be published.

Open Access This article is distributed under the terms of the Creative Commons Attribution 4.0 International License (http:// creativecommons.org/licenses/by/4.0/), which permits unrestricted use, distribution, and reproduction in any medium, provided you give appropriate credit to the original author(s) and the source, provide a link to the Creative Commons license, and indicate if changes were made. 


\section{References}

1. Moriyama T, Relling MV, Yang JJ (2015) Inherited genetic variation in childhood acute lymphoblastic leukemia. Blood 125(26):3988-3995. https://doi.org/10.1182/blood-2014-12 580001

2. Karran P, Attard N (2008) Thiopurines in current medical practice: molecular mechanisms and contributions to therapy-related cancer. Nat Rev Cancer 8(1):24-36. https://doi.org/10.1038/nrc2292
3. Moriyama T, Nishii R, Perez-Andreu V, Yang W, Klussmann FA, Zhao X, Lin TN, Hoshitsuki K, Nersting J, Kihira K, Hofmann U, Komada Y, Kato M, McCorkle R, Li L, Koh K, Najera CR, Kham SK, Isobe T, Chen Z, Chiew EK, Bhojwani D, Jeffries C, Lu Y, Schwab M, Inaba H, Pui CH, Relling MV, Manabe A, Hori H, Schmiegelow K, Yeoh AE, Evans WE, Yang JJ (2016) NUDT15 polymorphisms alter thiopurine metabolism and hematopoietic toxicity. Nat Genet 48(4):367-373. https://doi.org/10.1038/ng.3508 